\title{
Prevalence of Brucella spp in humans ${ }^{1}$
}

\author{
Catharina de Paula Oliveira Cavalcanti Soares ${ }^{2}$ \\ José Andreey Almeida Teles ${ }^{3}$ \\ Aldenir Feitosa dos Santos ${ }^{4}$ \\ Stemberg Oliveira Firmino Silva ${ }^{5}$ \\ Maria Vilma Rocha Andrade Cruz $^{6}$ \\ Francisco Feliciano da Silva-Júnior?
}

Objective: to determine the seroprevalence of Brucella spp in humans. Method: this is an observational study, developed with 455 individuals between 18 and 64 years old, who use the Estratégia de Saúde da Família (Brazil's family health strategy). The serum samples of volunteers underwent buffered acid antigen tests, such as screening, agar gel immunodiffusion and slow seroagglutination test in tubes and 2-Mercaptoethanol. Results: among the samples, $1.98 \%$ has responded to buffered-acid antigen, $2.85 \%$ to agar gel immunodiffusion test and $1.54 \%$ to the slow seroagglutination tests on tubes/2-Mercaptoethanol. The prevalence of Brucella spp was $4.4 \%$, represented by the last two tests. Conclusion: the results of this research suggest that the studied population is exposed to Brucella spp infection.

Descriptors: Brucellosis; Prevalence; Human; Zoonosis.

\footnotetext{
${ }^{1}$ Paper extracted from master's thesis "Prevalência da Brucella SPP em Humanos", apresentada ao Centro Universitário Cesmac, Maceió, AL, Brazil.

2 Master's student, Centro Universitário Cesmac, Maceió, AL, Brazil. RN, Prefeitura Municipal de Marechal Deodoro, Marechal Deodoro, AL, Brazil. 3 Doctoral student, Universidade Federal Rural de Pernambuco, Recife, PE, Brazil. Full Professor, Centro Universitário Cesmac, Maceió, AL, Brazil. ${ }^{4}$ Post-doctoral fellow, Instituto de Química e Biotecnologia, Universidade Federal de Alagoas, Maceió, AL, Brazil. Full Professor, Centro Universitário Cesmac, Maceió, AL, Brazil. Full Professor, Universidade Estadual de Alagoas, Arapiraca, AL, Brazil.

5 Physician, Prefeitura Municipal de Arcoverde, Arcoverde, PE, Brazil.

${ }^{6}$ MSc, Full Professor, Centro Universitário Cesmac, Maceió, AL, Brazil.

7 PhD, Full Professor, Centro Universitário Cesmac, Maceió, AL, Brazil.
}

Corresponding Author:

Catharina de Paula Oliveira Cavalcanti Soares

Centro Universitário Cesmac

Rua Cônego Machado, 825

Bairro: Farol

CEP: 57051-160, Maceió, AL, Brasil

E-mail: inacavalcanti@hotmail.com
Copyright @ 2015 Revista Latino-Americana de Enfermagem This is an Open Access article distributed under the terms of the Creative Commons Attribution Non-Commercial License (CC BY-NC).

This license lets others distribute, remix, tweak, and build upon your work non-commercially, and although their new works must also acknowledge you and be non-commercial, they don't have to license their derivative works on the same terms. 


\section{Introduction}

Brucellosis is a health disorder. It is an infection-contagious disease caused by the bacteria of the genus Brucella, spread worldwide, with chronic evolution, showing diffuse granulomatous appearance and characterized by infection of cells of the mononuclear Phagocytic system, caused by facultative intracellular bacteria(1). $^{(1)}$.

Today ten species of the bacteria of Brucella genus are known, morphologically indistinguishable; however, each with its preferred host: $B$. melitensis: sheep and goats; Brucella abortus: bovine and bubaline; Brucella suis: swine, hares, reindeers and rodents; Brucella neotomae: desert rat; Brucella canis: canines; Brucella ovis: ovine; Brucella ceti: cetaceans; Brucella pinnipedialis: pinniped; Brucella microti: wood mouse and, most recently, Brucella inopinata: humans ${ }^{(2-5)}$.

By being able to affect animal and humans, it is considered an anthropozoonosis, because its etiologic agent - which lives in some animals - is transferable to the human species, and it is considered one of the most important health disorders spread worldwide, according to the Food and Agriculture Organization (FAO), the World Health Organization (WHO) and the World Organization for Animal Health (OIE) ${ }^{(6-7)}$.

In Brazil, in the 1970s, the Ministry of Agriculture, Livestock and Food Supply estimated a loss of US\$ 32 million caused by bovine or bubaline brucellosis, only considering animal abortions and the decrease in milk

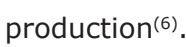

In humans it may have acute and latent forms. It is characterized by continuous, intermittent or irregular fever of uncertain duration, and has welldiversified diagnosis. A common symptom is asthenia and fatigue, accompanied by malaise, cephalalgia, weakness, profuse perspiration with characteristic smell, chills, arthralgia, depression, weight loss, as well as reproductive disorders such as orchitis and erectile dysfunction in men, and abortions and infertility in women, and may be asymptomatic or develop into the chronic form, in addition to osteoarticular complications, bacterial endocarditis and even suppuration of organs such as the spleen and the liver ${ }^{(8-9)}$.

Brucellosis is not a mandatory notifiable disease in Brazil for humans. However, in isolated cases, outbreaks of the disease must be reported, investigated and the control measures adopted, but the diagnosis becomes difficult due to its characterization $^{(8)}$.

The possibility of person-to-person transmission is uncertain, but probable since it was reported in Royal Oak, Michigan, in the United States, when the bacteria was isolated in an infected microbiologist's wife, suggesting the sexual contact as a possible source of infection ${ }^{(10)}$. A case study in Israel demonstrated the transmission between humans, associating the contamination of a doctor due to a newborn during resuscitation - the professional contracted $B$. melitensis after contact with the patient. The other members of the team involved had negative serology for bacteria(11).

The prevention of the disease in humans is related to positive animal control to this infection, in addition to a greater care with food and contact with contaminated sources. Vaccination is regulated for some animals, in the case of strains of Brucella abortus and Brucella melitensis. For humans studies are in progress, but nothing has been proven yet ${ }^{(12-13)}$.

The treatment is conducted with antibiotics, a combination of doxycycline and rifampin, for an average period of six weeks, in addition to other second-choice drugs, depending on the evolution of the clinical picture and the risk to patients such as children and pregnant women(14).

Although brucellosis is considered a potent infection in humans and animals, in Brazil we don't have an organized public health network capable of identifying human cases $^{(12)}$.

Due to the severity of the disease and the lack of epidemiological data on the situation of human brucellosis in the State and municipality, this research aimed at determining the seroprevalence of Brucella spp in the human population in the municipality of Marechal Deodoro, Alagoas, Brazil.

\section{Methods}

Our research is an observational study whose objective was to determine the seroprevalence of Brucella spp in the human population in the municipality of Marechal Deodoro, Alagoas, Brazil, estimated population of 45,977 inhabitants (of which 27,193 between 18 and 65 years old).

The sample size was calculated with a population of 27,193 , since we observed the disease prevalence was higher in adults $^{(1,15)}$, and the sample calculation performed had $95 \%$ of confidence limit, error of 
estimated prevalence of $5 \%$, and expected proportion of $50 \%$ - there was no research concerning the prevalence of brucellosis in humans in Brazil, thus $20 \%$ was added so losses could not compromise the representativeness of the sample. The total number of individuals selected was 455 with rounding.

The data were collected in the period from March to August 2013 at all Unidades de Saúde da Família (USF - Family health Units), in a way that any professional could approach the patient during his/her arrival in the waiting room, at the screening, vaccine or in the office.

The municipality has 15 Family Health Units under the Ministry of health $(\mathrm{MH})$, which have the records of residents. Previously we have carried out a calculation of how many individuals should be recruited, so every unit invited per month $20 \%$ of the sample during the five months of research. The amount of participants was proportional to the population of each USF.

For a better conduction of this study, screening cards were prepared to collect additional information of volunteers, in addition to folders and posters for disseminating information on brucellosis in the entire municipality.

All health care professionals were invited to participate in a meeting before the beginning of the research to discuss on the topic studied. Each USF representative received the material related to the study, e.g., screening sheets, educational material, informed consent terms and a manual on infectious and parasitic diseases by the Ministry of Health.

The invitation was delivered as a verbal request to patients who sought the health unit in the period, for any type of service, where they received all necessary information regarding the study in all its stages and undersigned the informed consent. To preserve anonymity the participants were identified by numbers. The doctor responsible for the USF has treated he positive cases when it was the case.

The blood samples were collected by venipuncture of the cephalic (or brachial) veins with $25 / 5$ needles, and a previous an antisepsis with alcohol $70 \%$ in the region. The volume of blood collected $( \pm 6 \mathrm{~mL}$ ) was kept in 10 $\mathrm{mL}$ test tubes that were inclined to help in the retraction process of the coagulum aiming at obtaining the serum for serological tests, which were later transferred to sterile microtubes and kept frozen at $-20^{\circ} \mathrm{C}$ until the performance of the tests. When performing serological tests, the samples were thawed and kept at room temperature. The material was subjected to buffered acid antigen tests (BAAT), slow seroagglutination test in tubes, 2-Mercaptoethanols (SAL/2-ME) and Agar Gel Immunodiffusion (AGID) test ${ }^{(16)}$. For the serological diagnosis of human brucellosis, kits produced by the Instituto de Tecnologia do Paraná (TECPAR) were used. The technique was performed also in accordance with the manufacturer's recommendations. Being the BAAT a screening test, the reagent serums underwent SALT/2ME to confirm the infection. All samples were tested with the AGID, being this a confirmatory test for rough species.

The samples collected were forwarded to the laboratory of Infection-Contagious Diseases of the Veterinary Medicine Course of CESMAC, located in the municipality of Marechal Deodoro, for processing.

For the Buffered Acid Antigen test, the Antigen used consisted of cell suspension of inactivated $B$. abortus (sample 1119-3) at a concentration of $8 \%, \mathrm{pH} 3.65$, colored with rose Bengal as shown below.

The serum and the antigen were kept at room temperature for 30 minutes before the test, and then deposited in standard squared plates, $30 \mu \mathrm{L}$ of serum to be tested and $30 \mu \mathrm{L}$ of the antigen. The homogenization of the serum and antigen was carried out with a glass rod, forming circles of approximately $2 \mathrm{~cm}$ (diameter). The plate was continuously agitated with oscillatory movements for 4 minutes, at a frequency of approximately 30 movements per minute, to allow the serum/antigen mixture flow slowly inside each circle(16) $^{(16}$

The reading was performed after the end of that period, and the results interpreted based on the agglutination reaction, which were indicated by the formation of coagula in positive serums and the absence of them in negative ones.

For the performance of the agargel immunodiffusion, a Borate buffer has been prepared and its $\mathrm{pH}$ adjusted to 8.3 through the addition of $0.2 \mathrm{M}$ sodium hydroxide solution. Then the gel was prepared with the addition of $1 \mathrm{~mL}$ of $1 \%$ sodium azide. After the complete dissolution by heat, $15 \mathrm{ml}$ of gel were spread on Petri dishes, no grooves at the bottom, and kept at room temperature until its solidification, stored at $2-8^{\circ} \mathrm{C}$ for at least 30 minutes and, on the outside, 24 hours. At the time of use, the gel was perforated with $6 \mathrm{~mm}$-diameter molds and with a distance of $2 \mathrm{~mm}$ between the edges - one central well and the other six arranged around it, each one with a capacity for $35 \mu \mathrm{L}$ of the material. After the agar removal, the wells were immediately 
filled with positive serums, serums to be tested and antigen (protocol used according to the manufacturer's recommendations: Instituto Tecnológico do Paraná).

Positive reagent serums (standard serum) were put in the upper and lower holes, in relation to the center hole, where the antigen was placed. The serums tested were placed in four side holes of the mold, and the plates kept in moist chamber at room temperature or in the lab stove at $20-25^{\circ} \mathrm{C}$.

The readings were performed after 24, 48 and 72 hours, using lighting system with indirect light and black background. The final result was obtained by the reading after 72 hours $^{(16)}$.

In the slow seroagglutination test in tubes, the antigen was composed of inactivated suspension of $B$. abortus (sample 1119-3), at a $4.5 \%$ concentration. The serum and the antigen remained for 30 minutes at room temperature before the test.

The antigen for slow seroagglutination was diluted at $1: 100$ in a $0.85 \%$ saline solution, with $0.5 \%$ phenol, at a final concentration of $0.045 \%$. Glass tubes were arranged in an appropriate bench, and $0.08 \mathrm{~mL}, 0.04 \mathrm{~mL}$, $0.02 \mathrm{~mL}, 0.01 \mathrm{~mL}$ of serum were put into each tube, 2 $\mathrm{ml}$ of $1: 100$ diluted antigen diluted $(0.045 \%$ of cells) in carbolic saline solution $(0.5 \%$ phenol), generating the respective dilutions: $25,50,100$ and 200 of serum. The samples were incubated in the stove, at a temperature of $37^{\circ} \mathrm{C}$ for a 48 -hour period when the reading would be carried out.

We considered as complete reaction the presence of a pellicle at the bottom of the tube and clear supernatant; and incomplete when pellicles at the bottom of the tube with slightly hazy supernatant. The negative reaction was represented by the absence of pellicle associated with hazy supernatant(16).

The 2-ME is a semiquantitative and selective test that detects only the presence of IgG in serum, which is the immunoglobulin that indicates chronic infection. This test should be performed always in parallel with the slow seroagglutination in tubes, based on the fact that IgM-class antibodies, with pentameric configuration, degrade themselves in subunits by the action of compounds with thiol radicals without generating complexes large enough to promote agglutination. Thus, serums with a predominance of IgM show negative reactions in this test and positive reactions for the slow test ${ }^{(16)}$.
The antigen was diluted at 1:50 in saline solution at $0.85 \%$ without phenol addition; the final concentration was $0.09 \%$, and the solution of $2-\mathrm{ME}$ at $0.1 \mathrm{M}$ was prepared blending $0.78 \mathrm{~mL}$ of $2-\mathrm{ME}$ at $99,22 \mathrm{~mL}$ of $0.085 \%$ saline solution without phenol. Four glass tubes were arranged in an appropriate bench, being deposited $0.08 \mathrm{~mL}, 0.04 \mathrm{~mL}, 0.021 \mathrm{~mL}$ and $0.01 \mathrm{~mL}$ of the serums to be tested, to which were added $1 \mathrm{~mL}$ of 2-ME $0.1 \mathrm{M}$ and, after 15 minutes, $1 \mathrm{~mL}$ of the diluted antigen, corresponding to 25, 50, 100 and 200 dilutions, respectively. The tubes were incubated at $37^{\circ} \mathrm{C}$ in a 48-hour period and then the reading was performed. The reading the reactions followed the same pattern observed for $\mathrm{SAL}^{(16)}$.

This research was approved by the Ethics Committee on Research and Teaching of Centro Universitário Cesmac (COEPE), registration no. 25000.196371/201170 CONEP/CNS/SIPAR/MS - 11/10/2011, under Protocol no. $1661 / 12$.

\section{Results}

Of the 455 samples evaluated, $1.98 \%$ had positive results for BAAT, $1.54 \%$ for SAL/2-ME and $2.85 \%$ for the AGID test. The latter two tests characterize positive samples in the population studied (Table 1 ).

Table 1 - Serological results for brucellosis in the 455 samples evaluated. Marechal Deodoro, AL, Brazil, 2014

\begin{tabular}{lccccc}
\hline \multirow{2}{*}{ Test } & \multicolumn{5}{c}{ Samples } \\
\cline { 2 - 5 } & Positive & $\%$ & Negative & $\%$ & Total \\
\hline BAAT* $^{*}$ & 9 & 1.98 & 446 & 98.02 & 455 \\
SALT/2 ME $^{\dagger}$ & 7 & 1.54 & 448 & 98.46 & 455 \\
AGID $^{\ddagger}$ & 13 & 2.86 & 442 & 97.14 & 455 \\
\hline
\end{tabular}

* BAAT - buffered acid antigen test

+ SALT/2-ME - 2-Mercaptoethanol test

₹ AGID- agar gel immunodiffusion test

Of the 455 participants, $20(4.4 \%)$ had the infection, $17(85 \%)$ women and $3(15 \%)$ men. Of the total of the population studied, 341 (74.95\%) were women and 114 (25.05\%) men. Pregnant women were not identified during the research. We observed that $11(55 \%)$ individuals with reagent results had direct contact with animal species, such as bovine, porcine, canine, ovine, caprine or equine (Figure 1). 


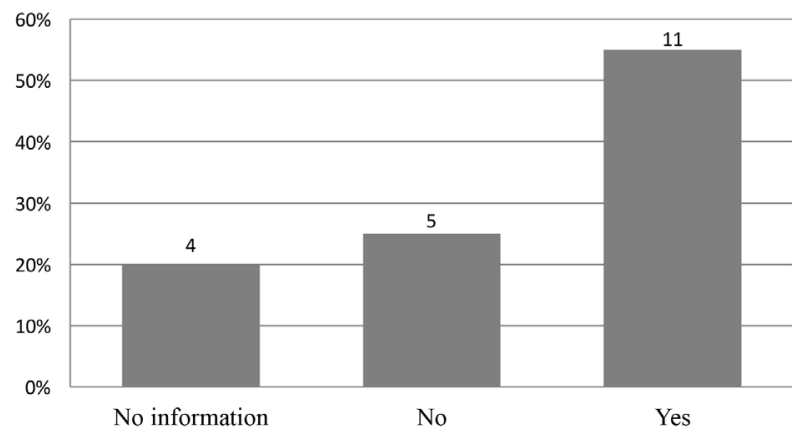

Figure 1 - Total of Brucella-positive individuals who had or not contact with animal species. Marechal Deodoro, AL, Brazil, 2014

According to the eating habits of the participants, $10(50 \%)$ Brucella-positive cases in this research claimed to drink raw milk and/or derivatives.

People contaminated by Brucella spp infection had between 20 and 64 years old, an average of 41.8 years and standard deviation of 15 .

Regarding employments, most of the positive cases, 9 (45\%), were housewives. The other professional activities were described as the follows: 2 (10\%) practical nurses, 2 (10\%) community health agents, 1 (5\%) retired, 1 (5\%) maid, 1 (5\%) administrative assistant, 1 (5\%) secretary, 1 (5\%) peasant, 1 (5\%) professional housekeeper and 1 (5\%) handicraftsman.

Among the clinical symptoms reported in the screening sheets, it was observed that most people mentioned cephalalgia, followed by malaise, profuse perspiration, weight loss, fatigue and irregular fever. Eight $(40 \%)$ volunteers have mentioned more than one symptom and 8 (40\%) reported no symptoms (Figure 2).

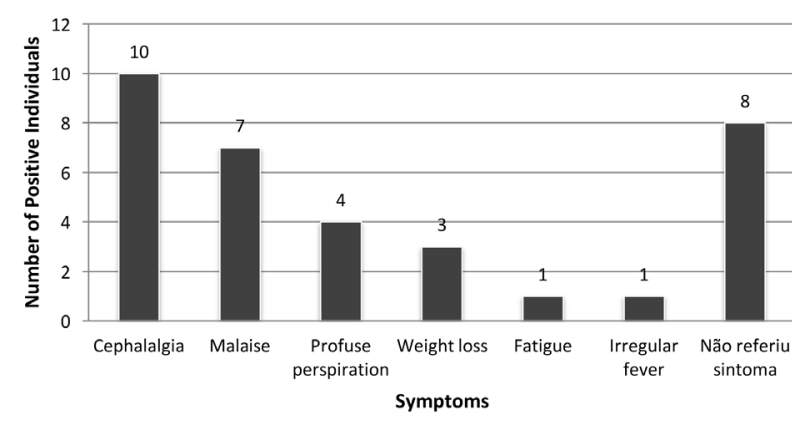

Figure 2 - Symptoms reported by Brucella-positive patients. Marechal Deodoro, AL, Brazil, 2014

\section{Discussion}

This study highlights the prevalence of Brucella spp of $4.4 \%$ in humans. However, it is worth mentioning that there is no data about the disease in the municipality analyzed, and even in the State and country in which it is located. According to the scientific literature, it is understood that the incidence of brucellosis can be up to five times higher, due to underreporting and to the difficult diagnosis(1).

Diverging from data of other geographical realities, the infection was found in a higher ratio in men (2:1). This study demonstrated higher prevalence in females, possibly because men seek less hospital care. According to a qualitative research carried out in Rio de Janeiro, RJ, with two groups of men with different educational level (having more than 40 years and who work or live in the city), it was proved that those seeking less health services, whether for the fear of discovering an illness, shyness or reasons imposed by society(17).

In Turkey, 1,028 medical records of patients infected with Brucella were analyzed - $52.4 \%$ were female and $47.6 \%$ male. Despite this prevalence, one can not say that the Brucellosis has a predilection for the female body, precisely because woman is the one who most often seek health services ${ }^{(18)}$. It is understood that, perhaps, the absence of a specific notification service for brucellosis can mask the real incidence of the disease and its variables.

Regarding age, researches indicate that the disease is more common in adults aged between 55 and 64 years $^{(1)}$.

In China, an epidemiological assessment showed positive cases that occurred between 2004 and 2010, through the country's notification of diseases system, where it was possible to notify 162,329 cases of human brucellosis in 1,201 of 2,922 municipalities, with a peak of cases in the spring and summer, predominantly in men - more than half of the cases was between 30 and 49 years old. In China, brucellosis is a mandatory notifiable disease, both in humans and animals ${ }^{(4,19)}$. However, this study is partially in accordance with the scientific literature, in which the studied population presented age ranged from 20 to 64 years. But there were limitations related to the selection of these individuals, because only persons over 18 and under 64 years old were invited. 
The bacteria transmission to humans may occur by direct contact with sick animals, ingestion of raw milk and its derivatives, consumption of contaminated animal meat. Moreover, there is the possibility of transmission from person to person, what makes these findings even more worrisome, because sexual partners can be also infected. These are some potential sources of contamination, which may bring serious consequences to public health ${ }^{(8,20)}$.

Thus, in this study we can conclude that the volunteers with Brucella possibly acquired the bacteria through the contact with animals and/or consuming contaminated food.

Usually the brucellosis is related to the occupation, and in this research we can not relate the infection with such variable, since various professions were reported. A case study in China has detected the presence of Brucella in a mother and her twins - the contamination has not occurred in the work environment, but due to the dietary habits of the mother, thus leading to a vertical transmission and an increased probability of contracting the bacteria people until now considered to be in the low-risk group $^{(21)}$.

Due to the close relationship between humans and animals, zoonoses and other diseases transmitted by food of animal origin are particularly important. In most poor countries, there is little investment in public health services, and, as a result, the operation of health surveillance is impaired. Nevertheless, there is a trend to search for improvements in the control of brucellosis, since the advancement of technology permits the access to information around the world ${ }^{(22)}$.

Concerning symptomatology, the literature characterizes brucellosis as an illness of diversified clinic; among the symptoms observed are continuous fever, asthenia, fatigue, cephalalgia, profuse sweating, weight loss and others ${ }^{(9,18)}$. The recognition of brucellosis as a human disease becomes complex, precisely due to the non-specificity of symptoms. This infection can reach all organs of the body, so laboratory diagnosis is necessary(23).

Of the symptoms pointed out in this research, the cephalalgia was the most common and can be correlated with the literature - such complaint has been one of the most prevalent in the acute phase of the infection. Thus, one can understand that these patients are included in the initial phase of the disease and the others, asymptomatic bearers, with possibility of also being in the chronic phase ${ }^{(1.9)}$.

If the patient has fever, fatigue, malaise or other brucellosis symptom, and if he or she lives in an endemic location for other diseases of similar course, and there are risk factors, such as direct contact with animals and life in rural areas, careful research is necessary to put aside or diagnose the disease ${ }^{(24)}$.

While human brucellosis in Brazil is poorly known, with scarce and neglected data, in various parts of the world it has been considered a common disease for decades, and people have been facing challenges for its eradication and control. It is important to emphasize that our country recognize animal brucellosis as an important zoonosis, but ignore the infection in humans - the disease is present in several herds and Brazil is situated almost at the same level of countries considered endemic, such as Peru and Argentina(12,24-25).

\section{Conclusion}

The human population of Marechal Deodoro showed prevalence of $4.4 \%$ for Brucella spp. Before the conclusion of this research, the reality of the city studied, in regards to brucellosis, was absolutely unknown, since there was no records of the disease in the Notifiable Diseases Information System (SINAN), or any data or technical note on the topic for health care professionals. Thus, consequently, the population was not oriented by health services. On the assumption that the infection is very relevant to public health, it is necessary disseminate more information through posters and folders, which were suggested to the Municipal Secretariat of Health before the conduction of this research. Therefore, considering the prevalence of Brucella spp found, the implementation of public policies to treat brucellosis in humans can be deemed urgent, in addition to the inclusion of the disease in the mandatory notifiable diseases category, and the structuralization of the epidemiological surveillance service to know the epidemiological profile and ensure 
flow of health service and clinical management for patients bearers of Brucella spp, in Marechal Deodoro, Alagoas, Brazil.

\section{Study limitations}

We could relate the limitations of this study to the fact that the individuals were in the age group between 18 and 64 years, and can not represent the entire population. Another limitation is related to the selection of the sample, which excluded the possibility of inviting other residents that have not sought health services during the period.

\section{Acknowledgments}

To the volunteers who participated in the research and the staff of family health units.

\section{References}

1. Pessegueiro P, Barata C, Correia J. Brucelose-uma revisão sistematizada. Medicina Interna. 2003;10(2):91100.

2. Foster G, Osterman B S, Godfroid J, Jacques I, Cloeckaert A. Brucella ceti sp. nov.and Brucella pinnipediali ssp.nov. for Brucella strains with cetaceans and seals as their preferred hosts. Int J System Evol Microbiol. 2007;57:2688-93.

3. Scholz HC, Nöckler K, Göllner C, Bahn P, Vergnaud $\mathrm{G}$, Tomaso $\mathrm{H}$, et al. Brucella inopinata sp. nov., isolated from a breast implant infection. Int J Syst Evol Microbiol. 2010;60:801-8.

4. McDonald $W L$, Jamaludin $R$, Mackereth $G$, Hansen M, Humphrey $S$, Short $P$, et al. Characterization of a Brucella sp. strain as a marine-mammal type despite isolation from a patient with spinal osteomyelitis in New Zealand. J Clin Microbiol. 2006;44(12):4363-70.

5. Tiller RV, Gee JE, Frace MA, Taylor KT, Setubal JC, Hoffmaster AR, et al. Characterization of Novel Brucella Strains Originating from Wild Native Rodent Species in North Queensland, Australia. Appl Environ Microbiol. 2010;76:5837-45.

6. Poester FP, Gonçalves VSP, Lage AP. Brucellosis in Brazil. Vet Microbiol. 2002;90:55-62.

7. Li ZJ, Cui BY, Chen H, Chen JD, Zhao HY, Piao DR, et al. Molecular Typing of Brucella Suis Collected from 1960s to 2010s in China by MLVA and PFGE. Biomed Environ Sci. 2013;26(6):504-8.
8. Ministério da Saúde (BR). Secretaria de Vigilância em Saúde. Departamento de Vigilância Epidemiológica. Doenças infecciosas e parasitárias: guia de bolso. Brasília: Ministério da Saúde; 2010.

9. Dean AS, Crump L, Greter H, Hattendorf J, Schelling E, Zinsstag J. Clinical manifestations of human brucellosis: a systematic review and meta-analysis. PLoS Negl Trop Dis. 2012; 6(12):e1929. doi: 10.1371/journal. pntd.0001929. Epub 2012 Dec 6.

10. Ruben B, Band JD, Wong P, Colville J. Person-toperson transmission of Brucella melitensis. Lancet. 1991;337(8732):14-5.

11. Mesner O, Riesenberg $\mathrm{K}$, Biliar N, Borstein E, Bouhnik L, Peled N, et al. The many faces of human-to-human transmission of brucellosis: congenital infection and outbreak of nosocomial disease related to an unrecognized clinical case. Clin Infect Dis. 2007;45(12):e135-40. doi: $10.1086 / 523726$.

12. Lawinsky MLJ, Ohara PM, Elkhoury MR, Faria NC, Cavalcante KRLJ. Estado da arte da brucelose em humanos. Rev Pan-Amaz Saude. 2010;1(4):75-84.

13. Corbel MJ. Brucellosis: an overview. Emerg Infect Dis. $1997 ; 3(2): 213-21$.

14. Solera J. Update on brucellosis: therapeutic challenges. Int J Antimicrob Agents. 2010;36(1):518-20.

15. Turan H, Serefhanoglu K, Karadeli E, Togan T, Arslan H. Osteoarticular involvement among 202 brucellosis cases identified in Central Anatolia region of Turkey. Intern Med. 2011;50(5):421-8.

16. Alton GG, Jones LM, Pietz DE. Las técnicas de laboratorio de la brucelosis. 2.ed. Geneva: WHO; 1976. (Série de Monografías, 55, p. 68-133).

17. Gomes R, Nascimento EF, Araújo F. Por que os homens buscam menos os serviços de saúde do que as mulheres? As explicações de homens com baixa escolaridade e homens com ensino superior. Cad Saúde Pública. 2007;23(3):565-74.

18. Buzgan T, Karahocagil MK, Irmak H, Baran AI, Karsen $H$, Evirgen $O$ et al. Clinical manifestations and complications in 1028 cases of brucellosis: a retrospective evaluation and review of the literature. Int J Infect Dis. 2010;14(6):e469-e78.

19. Li YJ, Li XL, Liang S, Fang LQ, Cao WC. Epidemiological features and risk factors associated with the spatial and temporal distribution of human brucellosis in China. BMC Infect Dis. 2013;13:547.

20. Vigeant $P$, Mendelson J, Miller MA. Human to human transmission of Brucella melitensis. Can J Infect Dis. $1995 ; 6(3): 153$. 
21. Chen S, Zhang H, Liu X, Wang W, Hou S, Li T, et al. Increasing threat of brucellosis to low-risk persons in urban settings, China. Emerg Infect Dis. 2014;20(1)12030.

22. McDermott J, Grace D, Zinsstag J. Economics of brucellosis impact and control in low-income countries. Revue scientifique et technique (International Office of Epizootics). 2013;32(1):249-61.

23. Galińska EM, Zagórski J. Brucellosis in humansetiology, diagnostics, clinical form. Ann Agric Environ Med. 2013;20(2):233-8.

24. Pappas G, Papadimitriou P, Akritidis N, Christou L, Tsianos EV. The new global map of human brucellosis. Lancet Infect Dis. [Internet]. fev 2006 [acesso 18 jan 2013];6(2): Disponível em: http://bvs.panalimentos. org/pdf

25. Poester FP, Figueiredo VCFD, Lôbo JR, Gonçalves VSP, Lage AP, Roxo E, et al. Estudos de prevalência da brucelose bovina no âmbito do Programa Nacional de Controle e Erradicação de Brucelose e Tuberculose: Introdução. Arq Bras Med Vet Zootec. 2009;61(1):1-5. 